\title{
Hemophagocytic lymphohistiocytosis in a patient with influenza and invasive pulmonary aspergillosis - A case report
}

\author{
Schouten MGJ* and van der Hoeven JG \\ Department of Intensive Care, University Medical Center, Nijmegen, The Netherlands
}

\begin{abstract}
Invasive pulmonary aspergillosis can occur secondary to influenza pneumonia and has a high mortality. We present a case of a previously healthy 38 -year-old woman suffering from influenza pneumonia complicated by IAA. She also met the criteria for hemophagocytic lymphohistcytosis (HLH), without signs of immunocompromised state. Despite extensive treatment, the patient did not survive. We review the existing literature of HLH in influenza cases.
\end{abstract}

\section{Introduction}

Invasive pulmonary aspergillosis (IAA) is a complication that can develop in patients with influenza pneumonia. In a review of 68 cases of influenza associated aspergillosis, overall mortality rate in this specific group was $47 \%$ [1]. In a retrospective cohort study of influenza-A (H1N1) patients, Wauters et al. [2] found that use of corticosteroids is an independent risk factor for developing secondary fungal infections. However, a recent retrospective observational study in academic intensive care patients in the Netherlands showed that not all fatal IAA patients were immunocompromised. Five out of 23 patients with fatal IAA did not receive steroids nor had no underlying disease [3].

\section{Case history}

We present a case of a 38-year-old woman without a relevant previous medical history, who was admitted to our Intensive Care Unit (ICU) with respiratory failure caused by a combination of influenza-A infection and invasive pulmonary aspergillosis. The patient was initially admitted to another hospital with a severe community acquired respiratory infection caused by influenza-A. She was treated with antibiotics, steroids and high-flow nasal oxygen. She developed progressive respiratory insufficiency for which invasive mechanical ventilation was started and was subsequently transferred to our hospital.

Laboratory results showed leukocytosis of $43.910^{\star \star} 09 / 1$ with lymphocytopenia of $1 \%$, thrombocytopenia $<10010^{\star *} 09 / 1$ and a low hemoglobin level of $4.9 \mathrm{mmol} / \mathrm{l}$, C-reactive protein was $276 \mathrm{mg} / \mathrm{l}$. Computed Tomography (CT) scan of the thorax showed massive cavitations (Figure 1). A broncho-alveolar lavage was performed and was positive for influenza-A and aspergillus fumigatus. Aspergillus antigen was elevated in the lavage fluid (2.0) as well as in serum (1.3). All other cultures were negative.

The patient was treated with antiviral (oseltamivir) and antifungal (amfotericine-B and voriconazol) therapy. The pulmonary situation rapidly worsened and she needed extracorporeal $\mathrm{CO}_{2}$-removal as well as ventilation in prone position.
Despite appropriate treatment there was persistent fever and bicytopenia. Supplementary laboratory findings showed fibrinogen $8260 \mathrm{mg} / \mathrm{l}$, triglycerides $2.18 \mathrm{mmol} / \mathrm{l}$, ferritine $2961 \mathrm{ug} / \mathrm{l}$ and low NK cells. The combination of persisting fever, bicytopenia, high ferritine level, low NK cells and splenomegaly raised the suspicion of hemophagocytic lymphohistiocytosis. We started treatment with anakinra (interleukin-1 receptor antagonist). In-vitro tests showed a low immuneresponse to aspergillus. Therefore interferon-gamma was added to the treatment.

After three weeks of intensive treatment the clinical situation worsened and treatment was subsequently withdrawn. Postmortem examination showed fulminant invasive pulmonary aspergillosis (Figure 2). There were no intracerebral lesions or signs of an underlying malignancy. Unfortunately, bone marrow was not examined.

\section{Discussion}

We describe a previously healthy patient who developed influenza associated aspergillosis. During her stay at our ICU she showed signs of hemophagocytic lymphohistiocytosis (HLH). HLH can be devided in two types. The primary, or familial, HLH is a rare autosomal recessive disorder of multisystem inflammation, caused by gene mutations that affect activity of natural killer (NK) cells and T-lymphocytes. The secondary, or reactive, form of HLH can develop as a potential life threatening complication of several infections, malignancy and autoimmune disorders. Both types of HLH are characterized by overwhelming inflammation with expansion and activation of T-lymphocytes and hemophagocytic macrophages leading to a cytokine storm. The most important clinical features are fever,

Correspondence to: Schouten MGJ, Department of Intensive Care, University Medical Center, Nijmegen, The Netherlands, Tel: +31 6 41429720; E-mail: Schouten.MGJ@gmail.com

Key words: hemophagocytic lymphohistiocytosis, H1N1, influenza, pulmonary aspergillosis, anakinra

Received: August 02, 2017; Accepted: August 25, 2017; Published: August 28, 2017 


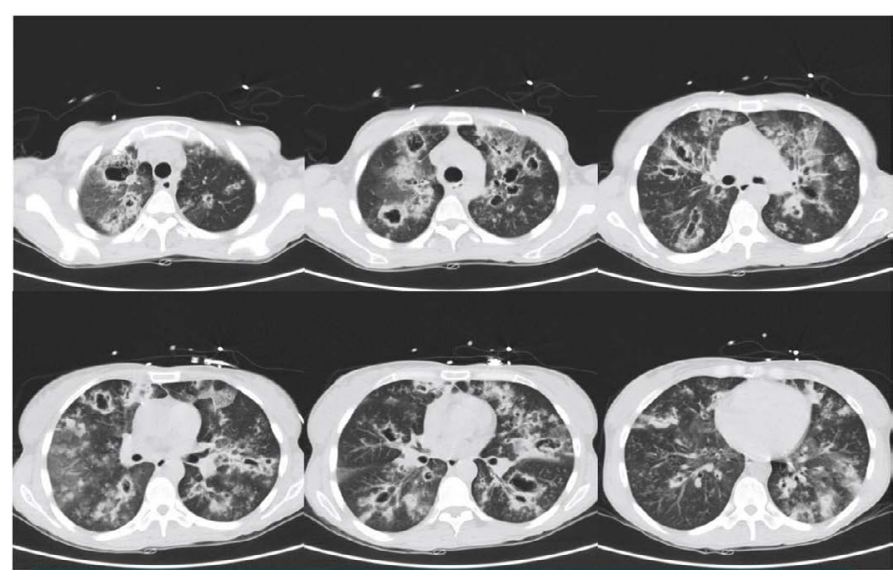

Figure 1. CT scan of the thorax shows massive cavitations.

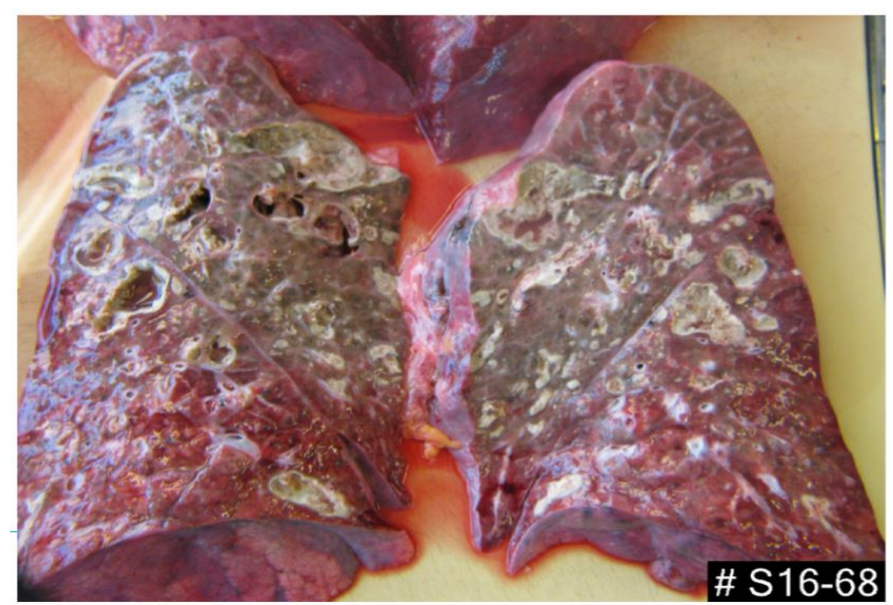

Figure 2. Postmortem examination of the lungs showed invasive aspergillosis (photograph taken during obduction).

Table 1. HLH-2004 diagnostic criteria [6].

The diagnosis HLH can be established if one of either 1 or 2 below is fulfilled

(1) A molecular diagnosis consistent with HLH

(2) Diagnostic criteria for HLH fulfilled (five out of the eight criteria below)

(A) Initial diagnostic criteria (to be evaluated in all patients with HLH)

Fever

Splenomegaly

Cytopenias (affecting $\geq 2$ of 3 lineages in the peripheral blood):

Hemoglobin $<90 \mathrm{~g} / \mathrm{L}$ (in infants $<4$ weeks: hemoglobin $<100 \mathrm{~g} / \mathrm{L}$ ), platelets $<100 \times$

$10^{9} / \mathrm{L}$, neutrophils $<1.0 * 10^{9} / \mathrm{L}$

Hypertriglyceridemia and/or hypofibrinogenemia

Fasting triglycerides $>3.0 \mathrm{mmol} / \mathrm{L}$ (i.e., $\geq 265 \mathrm{mg} / \mathrm{dl}$ )

Fibrinogen $\leq 1.5 \mathrm{~g} / \mathrm{L}$

Hemophagocytosis in bone marrow or spleen or lymph nodes

No evidence of malignancy

\section{(B) New diagnostic criteria}

Low or absent NK-cell activity (according to local laboratory reference)

Ferritin $\geq 500 \mathrm{mg} / \mathrm{L}$

Soluble CD25 (i.e., soluble IL-2 receptor) $\geq 2,400 \mathrm{U} / \mathrm{ml}$

hepatosplenomegaly, cytopenias, coagulopathy with low fibrinogen levels, liver dysfunction, hypertriglyceremia and hyperferritinemia [46]. The diagnosis is usually made using a combination of laboratory findings and clinical features, the HLH-2004 criteria (Table 1) [6].

Treatment of HLH is theoretically based on three approaches. First, supportive care because of the frequent life-threatening symptoms at presentation of the disease. Second, treatment of the underlying disease is essential to take away the primary trigger. Third, the massive inflammatory response needs treatment, with immunosuppressive drugs such as ciclosporin or cytotoxic drugs like chemotherapeutics [7]. In some cases treatment with intravenous immunoglobuline therapy has been successful in HLH cases [8,9]. There are reports of successful use of biological agents such as etanercept and infliximab in patients with refractory HLH $[10,11]$. Also anakinra, an interleukine-1 receptor antagonist, has been shown to control the inflammatory response. There are case series in which it is successfully used in the treatment of hyperinflammatory syndromes without worsening of cytopenias $[12,13]$.

Shulert et al. [5] described 16 fatal H1N1 influenza-A cases in which the diagnostic criteria for HLH were present in $31-81 \%$ of the patients. They also reported a high frequency of mutations in HLH associated genes in these patients. This suggests a genetic predisposition to developing a hyper-inflammatory response in case of severe H1N1 infection in these patients. In our patient we chose, apart from treatment of the disease, for control of the inflammatory response with anakinra.

\section{Conclusion}

We presented a patient with influenza associated aspergillosis and signs of hemophagocytic lymphohistiocytosis. Despite having high fibrinogen levels and no severe hypertriglyceremia, our patient met the criteria for HLH. The pathogenesis of HLH secondary to H1N1 is not fully understood, but there might be a genetic predisposition in these patients to developing a hyper-inflammatory response in case of severe H1N1 infection. Anakinra may be an alternative treatment for these patients.

\section{References}

1. Alshabani K, Haq A, Miyakawa R, Palla M, Soubani AO (2015) Invasive pulmonary aspergillosis in patients with influenza infection: report of two cases and systematic review of the literature. Exp Rev Resp Med 9: 89-96. [Crossref]

2. Wauters J, Baar I, Meersseman P, Meersseman W, Dams K, et al. (2012) Invasive pulmonary aspergillosis is a frequent complication of critically $11 \mathrm{H} 1 \mathrm{~N} 1$ patients: a retrospective study. Intens Care Med 38: 1761-1768. [Crossref]

3. van de Veerdonk FL, Kolwijck E, Lestrade PP, Hodiamont CJ, Rijnders BJ, et al. (2017) Influenza-Associated Aspergillosis in Critically Ill Patients. Am J Respir Crit Care Med. [Crossref]

4. Schulert GS, Grom AA (2015) Pathogenesis of macrophage activation syndrome and potential for cytokine-directed therapies. AnnuRevMed 66: 145-159. [Crossref]

5. Schulert GS, Zhang M, Fall N, Husami A, Kissell D, et al. (2016) WholeExome Sequencing Reveals Mutations in Genes Linked to Hemophagocytic Lymphohistiocytosis and Macrophage Activation Syndrome in Fatal Cases of H1N1 Influenza. J InfectDis 213: 1180-1128. [Crossref]

6. Henter JI, Horne A, Aricó M, Egeler RM, Filipovich AH, et al. (2007) HLH-2004: Diagnostic and therapeutic guidelines for hemophagocytic lymphohistiocytosis. Pediatr Blood Cancer 48: 124-131. [Crossref]

7. Ramos-Casals M, Brito-Zerón P, López-Guillermo A, Khamashta MA, Bosch X (2014) Adult haemophagocytic syndrome. Lancet 383: 1503-16. [Crossref]

8. Emmenegger U, Spaeth PJ, Neftel KA (2002) Intravenous immunoglobulin for hemophagocytic lymphohistiocytosis? J Clin Oncol 20: 599-601. [Crossref]

9. Larroche C, Bruneel F, André MH, Bader-Meunier B, Baruchel A, et al. (2008) Intravenously administered gamma-globulins in reactive hemaphagocytic syndrome. Multicenter study to assess their importance, by the immunoglobulins group of experts of CEDIT of the AP-HP. Ann Med Interne (Paris) 151: 533-539. [Crossref]

10. Takahashi N, Naniwa T, Banno S (2008) Successful use of etanercept in the treatment of acute lupus hemophagocytic syndrome. Mod Rheumatol 18: 72-75. [Crossref]

11. Henzan T, Nagafuji K, Tsukamoto H, Miyamoto T, Gondo H, et al. (2006) Success with infliximab in treating refractory hemophagocytic lymphohistiocytosis. Am J Hematol 81: 59-61. [Crossref] 
Schouten MGJ (2017) Hemophagocytic lymphohistiocytosis in a patient with influenza and invasive pulmonary aspergillosis - A case report

12. Rajasekaran S, Kruse K, Kovey K, Davis AT, Hassan NE, et al. (2014) Therapeutic role of anakinra, an interleukin-1 receptor antagonist, in the management of secondary hemophagocytic lymphohistiocytosis/sepsis/multiple organ dysfunction/macrophage activating syndrome in critically ill children. Pediatr Crit Care Med 15: 401-408. [Crossref]
13. Bruck N, Suttorp M, Kabus M, Heubner G, Gahr M, Pessler F (2011) Rapid and sustained remission of systemic juvenile idiopathic arthritis-associated macrophage activation syndrome through treatment with anakinra and corticosteroids. $J$ Clin Rheumatol 17: 23-27. [Crossref]

Copyright: (C2017 Schouten MGJ. This is an open-access article distributed under the terms of the Creative Commons Attribution License, which permits unrestricted use, distribution, and reproduction in any medium, provided the original author and source are credited. 